\title{
Correction to: Optimization of abrasive waterjet machining using multi-objective cuckoo search algorithm
}

\section{Zhengrong Qiang $^{1} \cdot$ Xiaojin Miao $^{1} \cdot$ Meiping Wu ${ }^{1} \cdot$ Rapinder Sawhney ${ }^{2}$}

Published online: 1 November 2019

(C) Springer-Verlag London Ltd., part of Springer Nature 2019

Correction to: The International Journal of Advanced Manufacturing Technology, Volume 99, Issue 5-8, pp 1257-1266

https://doi.org/10.1007/s00170-018-2549-x

Author Meiping Wuwmp169@jiangnan.edu.cn should also be declared as the corresponding author of the article https:// doi.org/10.1007/s00170-018-2549-x.

Publisher's note Springer Nature remains neutral with regard to jurisdictional claims in published maps and institutional affiliations.

The online version of the original article can be found at https://doi.org/ $10.1007 / \mathrm{s} 00170-018-2549-\mathrm{x}$

Zhengrong Qiang

qiangzhengrong001@ hotmail.com

Meiping Wu

wmp169@jiangnan.edu.cn

1 School of Mechanical Engineering, Jiangnan University, Wuxi 214122, China

2 School of Industrial and Systems Engineering, University of Tennessee, Knoxville, TN 37996-2315, USA 